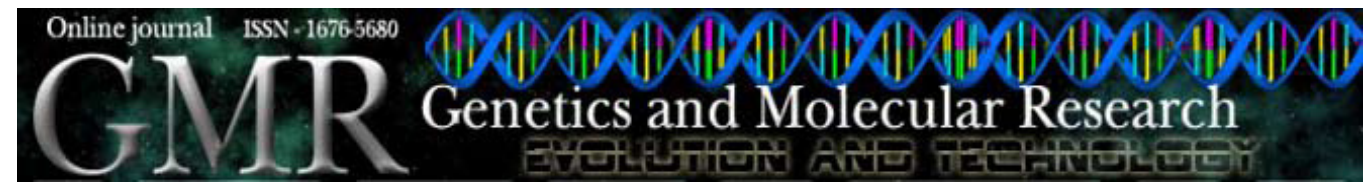

\title{
Genotype and allele frequencies of $M D R 1$ gene C1236T polymorphism in a Turkish population
}

\author{
G. Gümüş-Akay ${ }^{1}$, A. Rüstemoğlü ${ }^{2}$ A. Karadağ $\breve{~}^{1}$ and A. Sunguroğlu ${ }^{1}$ \\ ${ }^{1}$ Department of Medical Biology, Faculty of Medicine, Ankara University, \\ Ankara, Turkey \\ ${ }^{2}$ Department of Medical Biology, Faculty of Medicine, \\ Gaziosmanpaşa University, Tokat, Turkey \\ Corresponding author: G. Gümüş-Akay \\ E-mail: guvemg@yahoo.com
}

Genet. Mol. Res. 7 (4): 1193-1199 (2008)

Received July 21, 2008

Accepted September 5, 2008

Published October 28, 2008

ABSTRACT. Human P-glycoprotein (P-gp) is encoded by the MDRl gene, which is located on chromosomal region $7 \mathrm{q} 21$ and consists of 28 exons. To date, over 50 single nucleotide polymorphisms (SNPs) have been reported for the MDRl gene. The effect of these polymorphisms on P-gp function or their clinical impact is in most cases unknown, but some of the SNPs are known to be of functional relevance and can also alter the pharmacokinetics of substrate drugs. The aim of the current study was to analyze for the first time an existing silent MDR1 C1236T (Gly412Gly) polymorphism in a Turkish population. The genotype frequencies of C1236T SNP in a Turkish population were also compared with those in other populations. One hundred unrelated healthy subjects (48 females, 52 males) were included in this study and all them were of Turkish ethnicity. The genotyping of the C1236T SNP was performed by the polymerase chain reaction (PCR)-restriction fragment length polymorphism (RFLP) method. The frequencies of the wild-type $\mathrm{C}$ and mutant $\mathrm{T}$ alleles were 45.5 and $54.5 \%$, respectively. The distribution of $\mathrm{C} 1236 \mathrm{~T}$ genotype frequencies in our study group was found to be similar to that in Czech, Polish, Portuguese, Russian, Malay, and Japanese populations and different from that in French, German, Chinese, and Indian populations. The distributions of $\mathrm{CC}, \mathrm{CT}$, and TT genotypes were $20.0,51.0$, and $29.0 \%$, respectively. Our study provides a framework for future studies concerning the role of polymorphic variants of $M D R 1$ gene 
in the genesis of various diseases or in designing future pharmacogenetic and pharmacokinetic studies conducted with P-gp substrates in the Turkish population.

Key words: MDR1; C1236T; Polymorphism; Turkish population

\section{INTRODUCTION}

A key pharmacological barrier limiting the accessibility of drugs to various critical target tissues and cells is P-glycoprotein (P-gp), also known as ABCB1 or MDR1. This protein is a member of the ATP binding cassette (ABC) super-family and composed of 1280 amino acids with two homologous halves containing six putative hydrophobic transmembrane segments and an intracellular binding site for ATP (Tang et al., 2002; Sakaeda, 2005). P-gp is an ATP-driven efflux pump, which is responsible for the altered pharmacokinetics of drugs that are P-gp substrates and for the multidrug resistance of cancer cells (Kimchi-Sarfaty et al., 2007a). P-gp transports a wide range of substances with diverse chemical structure including digoxin, quinidine, cyclosporine, etoposide, paclitaxel, rifampin, vinblastine, and vincristine (Schwab et al., 2003).

Human P-gp is also expressed in normal tissues including liver, kidneys, small and large intestines, brain, testis, muscle tissue, placenta, and adrenals (Sakaeda, 2005). Although the physiological role of P-gp is not fully understood, it is conceivable that P-gp may prevent intracellular accumulation of potentially toxic substances and metabolites (Schinkel, 1997). The important role of P-gp in tumorigenesis has been highlighted in animal models as shown in the development of colon, mammary and liver cancer (Kankesan et al., 2003, 2004; Mochida et al., 2003). For instance, the over-expression of P-gp has been associated with decreased proliferation activity and slower migration of enterocytes, leading to prolonged life span and resistance to apoptosis and resulting in an increasing chance of cell transformation (Mochida et al., 2003).

Human P-gp is encoded by the MDRl gene, which is located on chromosomal region $7 \mathrm{q} 21$ and consists of 28 exons ranging in size from 49 to $209 \mathrm{bp}$, and the cDNA spans $4.5 \mathrm{~kb}$ (Ambudkar et al., 2003; Ishikawa et al., 2004; Kimchi-Sarfaty et al., 2007b). To date, over 50 single nucleotide polymorphisms (SNPs) have been reported for MDR1 gene (http://www. ncbi.nlm.nih.gov/SNP/GeneGt.cgi?geneID=5243), of which more than 20 are known to be silent (Komar, 2007a).

Several preclinical and clinical studies have provided evidence for these naturally occurring SNPs of MDR1 and their effects on drug absorption, distribution and elimination (reviewed by Ishikawa et al., 2004). The effect of these polymorphisms on P-gp function or their clinical impact is in most cases unknown, but some of the SNPs are known to be of functional relevance and can also alter the pharmacokinetics of substrate drugs. Notably, the C3435T polymorphism in exon 26, polymorphism G2677T/A in exon 21, and C1236T polymorphism in exon 12 have been studied repeatedly in different populations and various disease conditions (Kroetz et al., 2003; Jamroziak et al., 2004; Xhemo et al., 2007; Kato et al., 2008).

Comparison between different polymorphism studies of the MDRl gene reveals a variation in frequencies of the heterozygous or homozygous genotypes among different populations. The present study analyzed for the first time an existing silent but functional MDRI C1236T (Gly412Gly) polymorphism in a Turkish population. The genotype frequencies of C1236T SNP in this Turkish population were also compared with those in other populations. 


\section{MATERIAL AND METHODS}

\section{DNA samples}

One hundred unrelated healthy subjects ( 48 females, 52 males) belonging to the Turkish population were included in this study. DNA samples used in this study were obtained from the DNA bank of the Department of Medical Biology, Ankara University Faculty of Medicine. All samples had been provided by persons previously participating in research projects conducted by the department with their written informed consent indicating permission for anonymous use of their DNA samples in other research studies. This study was approved by the Ankara University Research Ethics Committee of Medical Faculty with the approval \#119-3184.

\section{Identification of C1236T polymorphism}

A polymerase chain reaction (PCR)-restriction fragment length polymorphism (RFLP) was used for detection of C1236T (exon 12) SNP. PCR was performed in a $25-\mu \mathrm{L}$ total volume of reaction mixture containing $0.1 \mu \mathrm{g}$ genomic DNA, 10 pmol of each primer (forward: 5' TAT CCT GTG TCT GTG AAT TGC C 3'; reverse: 5' CCT GAC TCA CCA CAC CAA TG 3'), $0.2 \mathrm{mM}$ of each dNTP, $10 \mathrm{mM}$ Tris, $50 \mathrm{mM} \mathrm{KCl}, 2 \mathrm{mM} \mathrm{MgCl}{ }_{2}$ and $2 \mathrm{U}$ Taq DNA polymerase (GeneMark). PCR conditions were as follows: initial denaturation at $94^{\circ} \mathrm{C}$ for $2 \mathrm{~min}$ and then 35 cycles of $94^{\circ} \mathrm{C}$ for $30 \mathrm{~s}, 60^{\circ} \mathrm{C}$ for $30 \mathrm{~s}$, and $72^{\circ} \mathrm{C}$ for $30 \mathrm{~s}$ followed by a final extension at $72^{\circ} \mathrm{C}$ for $7 \mathrm{~min}$. Restriction digestion was performed in a total volume of $20-\mu \mathrm{L}$ reaction mixture containing $10 \mu \mathrm{L}$ PCR product and $40 \mathrm{U} B s n \mathrm{I}$ restriction endonuclease (GeneMark). Reaction mixtures were incubated at $37^{\circ} \mathrm{C}$ overnight and thermal inactivation was done at $80^{\circ} \mathrm{C}$ for $20 \mathrm{~min}$. Genotypes were determined by agarose gel electrophoresis of restriction digests on 3\% Nusieve GTG agarose (BMA) gel containing $0.5 \mu \mathrm{g} / \mathrm{mL}$ ethidium bromide.

\section{Statistical analysis}

Statistical analysis was performed using the Arlequin software, version 3.11. Allele and genotype frequencies for C1236T SNP in the study group were assessed for deviation from Hardy-Weinberg equilibrium using the Fisher exact test. F-statistics was used for comparing the genotype frequencies of different populations for the C1236T SNP. P $<0.05$ was considered to be statistically significant.

\section{RESULTS}

Samples of 100 healthy Turkish subjects were analyzed to detect the MDR1 C1236T polymorphism in exon 12 leading to no amino acid change. The allele and genotype frequencies of C1236T SNP are given in Table 1. The allele frequencies of C1236T SNP were 45.5 and $54.5 \%$ for wild-type $\mathrm{C}$ and mutant $\mathrm{T}$ alleles, respectively. The genotype frequency distributions of this SNP were CC: $20.0 \%$, CT: $51.0 \%$, and TT: $29.0 \%$. The expected heterozygosity was calculated as 0.496 . The observed genotype counts were consistent with those expected under the assumptions of Hardy-Weinberg equilibrium $(\mathrm{P}=0.84)$. 


\begin{tabular}{|c|c|c|c|c|c|c|c|}
\hline \multicolumn{4}{|c|}{ Allele frequencies } & \multicolumn{4}{|c|}{ Genotype frequencies } \\
\hline \multirow[t]{2}{*}{$\mathrm{C}$} & \multirow[t]{2}{*}{$\mathrm{T}$} & \multicolumn{2}{|c|}{$\mathrm{CC}$} & \multicolumn{2}{|c|}{$\mathrm{CT}$} & \multicolumn{2}{|c|}{ TT } \\
\hline & & Observed & Expected & Observed & Expected & Observed & Expected \\
\hline 0.4550 & 0.5450 & 0.20 & 0.2070 & 0.51 & 0.4960 & 0.29 & 0.2970 \\
\hline
\end{tabular}

When the genotype frequency distribution of C1236T polymorphism in the Turkish population was compared with that in other major populations, significant differences were found between the Turkish population and French, German, Chinese, and Indian populations $(\mathrm{P}<0.05)$. However, genotype frequency distribution of the C1236T SNP in our study group did not show any significant difference with respect to the Czech, Polish, Portuguese, Russian, Malay, and Japanese populations $(\mathrm{P}>0.05)$ (Table 2).

\begin{tabular}{|c|c|c|c|c|c|c|}
\hline \multirow[t]{2}{*}{ Population } & \multirow[t]{2}{*}{$\mathrm{N}$} & \multicolumn{3}{|c|}{$\mathrm{C} 1236 \mathrm{~T}$} & \multirow[t]{2}{*}{ FST } & \multirow[t]{2}{*}{ FST P } \\
\hline & & $\mathrm{CC}$ & $\mathrm{CT}$ & $\mathrm{TT}$ & & \\
\hline Turkish (present study) & 100 & 20.0 & 51.0 & 29.0 & - & - \\
\hline Czech & 189 & 31.7 & 47.1 & 21.2 & 0.00927 & $0.126 \pm 0.028$ \\
\hline French & 223 & 33.0 & 49.0 & 18.0 & 0.01666 & $0.009 \pm 0.009 *$ \\
\hline German & 461 & 34.4 & 49.2 & 16.4 & 0.02331 & $0.000 \pm 0.000 *$ \\
\hline Polish & 135 & 30.4 & 49.6 & 20.0 & 0.00650 & $0.18 \pm 0.043$ \\
\hline Portuguese & 100 & 27.0 & 55.0 & 18.0 & 0.00522 & $0.207 \pm 0.027$ \\
\hline Russian & 59 & 24.0 & 56.0 & 20.0 & -0.00427 & $0.576 \pm 0.036$ \\
\hline Chinese & 96 & 8.3 & 39.6 & 52.1 & 0.05368 & $0.000 \pm 0.000^{*}$ \\
\hline Indian & 87 & 13.8 & 37.9 & 48.3 & 0.03506 & $0.018 \pm 0.012 *$ \\
\hline Japanese & 154 & 11.0 & 46.8 & 42.2 & 0.01407 & $0.063 \pm 0.03$ \\
\hline Malay & 92 & 12.0 & 44.6 & 43.5 & 0.015 & $0.072 \pm 0.018$ \\
\hline
\end{tabular}

*Statistically significant difference.

\section{DISCUSSION}

Polymorphisms in the human genome contribute to wide variations in how individuals respond to medications, either by changing the pharmacokinetics of drugs or by altering the cellular response to therapeutic agents (Sauna et al., 2007). Analysis of the sequence of the human genome has shown that the extent of genetic variation in the human population is far greater than what had been estimated, and the most common sequence variation is the SNP, which occurs in about every 300 nucleotides (Buckland, 2006; Sauna et al., 2007).

A number of SNPs in the MDRI gene have already been identified as clinically important for drug response, raising the need for the genotyping of these SNPs in different populations for individualized drug treatment (Kimchi-Sarfaty et al., 2007b). Drug pharmacokinetics 
involving P-gp has often been found to be affected in individuals carrying various non-silent SNPs; however, sometimes changes have also been observed in individuals carrying silent SNPs (Komar, 2007a). To date, the most commonly reported polymorphism linked to different responses of patients to various MDR1 substrates is located at exon 26, C3435T, and does not result in an amino acid change. This silent polymorphism has been found to differ significantly amongst different populations (Tang et al., 2002; Jamroziak et al., 2004; Ramasamy et al., 2006; Kimchi-Sarfaty et al., 2007b). However, C3435T SNP has been associated with changes in the expression of MDR1 (Hoffmeyer et al., 2000; Larsen et al., 2007). Turgut et al. (2006) investigated the allelic and genotypic frequencies of the C3435T polymorphism in healthy individuals living in Denizli province of Turkey and reported 53.0\% heterozygosity for this polymorphic variant.

Another silent SNP in the MDR1 gene is the C1236T in exon 12 . C1236T polymorphism changes a GGC codon to GGT at amino acid position 412 of the polypeptide and both of them encode Gly (Kimchi-Sarfaty et al., 2007b). C1236T polymorphism has also been linked to the inter-individual differences of responses to various drugs. Xing et al. (2006) reported that the genotyping of $\mathrm{C} 1236 \mathrm{~T}$ may help to predict the efficacy of risperidone treatment on the basis that patients with the TT genotype showed greater improvement than those with other genotypes. It has been shown that the frequency of the mutant $\mathrm{T}$ allele was higher in late responders to oral prednisone than early responders for position 1236 in children with steroid-responsive nephrotic syndrome (Wasilewska et al., 2007). In the study of Bosch et al. (2006), the homozygous C1236T polymorphism in the MDR1 gene was correlated with a decreased docetaxel clearance. In addition, Aarnoudse et al. (2006) found that women with the TT genotype for position 1236 had a higher risk for the neuropsychiatric adverse effects of mefloquine. All these findings led to the idea that the genotyping of C1236T SNP in the MDR1 gene has an important role in studying the drug responses of different individuals. Therefore, it is necessary to know the allelic and genotypic frequencies of this SNP in different populations for individualized drug treatment.

A comparison between the genotype frequency distribution of C1236T SNP in the Turkish population and other populations from previous studies is summarized in Table 2. Our results show that genotype frequency distribution of C1236T SNP in our population is significantly different from that found in the French, German, Chinese, and Indian populations ( $\mathrm{p}<$ 0.05). The observed frequency of homozygous polymorphism in this study at this site (29.0\%) is very similar to that found in the Czech (21.2\%; Pechandova et al., 2006), Polish (20.0\%; Wasilewska et al., 2007), and Russian (20.0\%; Goreva et al., 2004) populations. However, the frequency of the 1236 TT genotype determined in the present study is lower than that reported in the Chinese (52.1\%; Chowbay et al., 2003), Indian (48.3\%; Chowbay et al., 2003), Malay (43.5\%; Chowbay et al., 2003), and Japanese (42.2\%; Komoto et al., 2006) populations, and higher than that observed in the French (18.0\%; Jeannesson et al., 2007), German (16.4\%; Cascorbi et al., 2001), and Portuguese (18.0\%; Jeannesson et al., 2007) populations. The homozygous CC genotype frequency detected in our study (20.0\%) is much closer to that in the Russian (24.0\%; Goreva et al., 2004) population. In contrast, the incidence of CC genotype in the Turkish population is lower than that observed in the Czech (31.7\%; Pechandova et al., 2006), French (33.0\%; Jeannesson et al., 2007), German (34.4\%; Cascorbi et al., 2001), Polish (30.4\%; Wasilewska et al., 2007), and Portuguese (27.0\%; Jeannesson et al., 2007) populations, and higher than that in the Chinese (8.3\%; Chowbay et al., 2003), Indian (13.8\%; 
Chowbay et al., 2003), Japanese (11.0\%; Komoto et al., 2006), and Malay (12.0\%; Chowbay et al., 2003) populations. As can be seen in Table 2, the homozygous TT genotype frequency is much higher in Asian populations than in European populations. In contrast, the wild-type CC genotype is more frequent in European populations than in Asian populations. In this respect, the frequencies of homozygous CC and TT genotypes in the Turkish population revealed intermediate characteristics when compared with the European and Asian populations most probably due to its geographical location.

Silent SNPs have largely been assumed to exert no discernible effect on gene function or phenotype. However, recent reports have changed this common view. Kimchi-Sarfaty et al. (2007a) showed that the substrate specificity of P-gp is altered by synonymous and silent SNPs. It has been suggested that silent SNPs may affect protein translation rates hence influencing protein folding and activity. Therefore, silent SNPs that do not change the coding sequence of the protein may contribute to altered pharmacokinetics of substrate drugs, and development and progression of certain disease conditions (Kimchi-Sarfaty et al., 2007a; Komar, 2007b; Sauna et al., 2007). Recent studies suggest that researchers studying SNPs should not neglect silent SNPs in determining the likelihood of the development and progression of diseases and these silent SNPs should be taken into account in individualized drug treatments (Komar, 2007b; Sauna et al., 2007). Over the last 5 years, a great deal of attention has been paid specifically to the silent C3435T polymorphism and, to a lesser extent, to the C1236T polymorphism. Therefore, analyzing the silent C1236T polymorphism in different populations is needed to better understand its unresolved functions in P-gp activity.

In conclusion, this is the first major study reporting the MDR1 C1236T genotype distribution in a Turkish population and finding a significant difference in the frequency compared to other populations, including French, German, Chinese, and Indian. Our study provides a framework for future studies concerning the role of polymorphic variants of MDRl gene in the genesis of various diseases or designing future pharmacogenetic and pharmacokinetic studies conducted with P-gp substrates in the Turkish population.

\section{ACKNOWLEDGMENTS}

Research supported by Ankara University Scientific Research Projects under project \#2007-08-09-046 HPD and approved by the Ankara University Research Ethics Committee of Medical Faculty with the approval \#119-3184.

\section{REFERENCES}

Aarnoudse AL, van Schaik RH, Dieleman J, Molokhia M, et al. (2006). MDR1 gene polymorphisms are associated with neuropsychiatric adverse effects of mefloquine. Clin. Pharmacol. Ther. 80: 367-374.

Ambudkar SV, Kimchi-Sarfaty C, Sauna ZE and Gottesman MM (2003). P-glycoprotein: from genomics to mechanism. Oncogene 22: 7468-7485.

Bosch TM, Huitema AD, Doodeman VD, Jansen R, et al. (2006). Pharmacogenetic screening of CYP3A and ABCB1 in relation to population pharmacokinetics of docetaxel. Clin. Cancer Res. 12: 5786-5793.

Buckland PR (2006). The importance and identification of regulatory polymorphisms and their mechanisms of action. Biochim. Biophys. Acta 1762: 17-28.

Cascorbi I, Gerloff T, Johne A, Meisel C, et al. (2001). Frequency of single nucleotide polymorphisms in the P-glycoprotein drug transporter MDR1 gene in white subjects. Clin. Pharmacol. Ther. 69: 169-174.

Chowbay B, Cumaraswamy S, Cheung YB, Zhou Q, et al. (2003). Genetic polymorphisms in MDR1 and CYP3A4 
genes in Asians and the influence of MDR1 haplotypes on cyclosporin disposition in heart transplant recipients. Pharmacogenetics 13: 89-95.

Goreva OB, Grishanova AY, Domnikova NP, Mukhin OV, et al. (2004). MDR1 gene C1236T and C6+139T polymorphisms in the Russian population: associations with predisposition to lymphoproliferative diseases and drug resistance. Bull. Exp. Biol. Med. 138: 404-406.

Hoffmeyer S, Burk O, von Richter O, Arnold HP, et al. (2000). Functional polymorphisms of the human multidrugresistance gene: multiple sequence variations and correlation of one allele with P-glycoprotein expression and activity in vivo. Proc. Natl. Acad. Sci. U. S. A. 97: 3473-3478.

Ishikawa T, Hirano H, Onishi Y, Sakurai A, et al. (2004). Functional evaluation of ABCB1 (P-glycoprotein) polymorphisms: high-speed screening and structure-activity relationship analyses. Drug Metab. Pharmacokinet. 19: 1-14.

Jamroziak K, Mlynarski W, Balcerczak E, Mistygacz M, et al. (2004). Functional C3435T polymorphism of MDR1 gene: an impact on genetic susceptibility and clinical outcome of childhood acute lymphoblastic leukemia. Eur. J. Haematol. 72: 314-321.

Jeannesson E, Albertini L, Siest G, Gomes AM, et al. (2007). Determination of ABCB1 polymorphisms and haplotypes frequencies in a French population. Fundam. Clin. Pharmacol. 21: 411-418.

Kankesan J, Yusuf A, Laconi E, Vanama R, et al. (2003). Effect of PSC 833, an inhibitor of P-glycoprotein, on 1,2-dimethylhydrazine-induced liver carcinogenesis in rats. Carcinogenesis 24: 1977-1984.

Kankesan J, Vanama R, Yusuf A, Thiessen JJ, et al. (2004). Effect of PSC 833, an inhibitor of P-glycoprotein on N-methyl$\mathrm{N}$-nitrosourea induced mammary carcinogenesis in rats. Carcinogenesis 25: 425-430.

Kato M, Fukuda T, Serretti A, Wakeno M, et al. (2008). ABCB1 (MDR1) gene polymorphisms are associated with the clinical response to paroxetine in patients with major depressive disorder. Prog. Neuropsychopharmacol. Biol. Psychiatry 32: 398-404.

Kimchi-Sarfaty C, Oh JM, Kim IW, Sauna ZE, et al. (2007a). A "silent" polymorphism in the MDR1 gene changes substrate specificity. Science 315: 525-528.

Kimchi-Sarfaty C, Marple AH, Shinar S, Kimchi AM, et al. (2007b). Ethnicity-related polymorphisms and haplotypes in the human ABCB1 gene. Pharmacogenomics 8: 29-39.

Komar AA (2007a). Silent SNPs: impact on gene function and phenotype. Pharmacogenomics 8: 1075-1080.

Komar AA (2007b). Genetics. SNPs, silent but not invisible. Science 315: 466-467.

Komoto C, Nakamura T, Sakaeda T, Kroetz DL, et al. (2006). MDR1 haplotype frequencies in Japanese and Caucasian, and in Japanese patients with colorectal cancer and esophageal cancer. Drug Metab. Pharmacokinet. 21: 126-132.

Kroetz DL, Pauli-Magnus C, Hodges LM, Huang CC, et al. (2003). Sequence diversity and haplotype structure in the human ABCB1 (MDR1, multidrug resistance transporter) gene. Pharmacogenetics 13: 481-494.

Larsen UL, Hyldahl Olesen L, Guldborg Nyvold C, Eriksen J, et al. (2007). Human intestinal P-glycoprotein activity estimated by the model substrate digoxin. Scand. J. Clin. Lab. Invest. 67: 123-134.

Mochida Y, Taguchi K, Taniguchi S, Tsuneyoshi M, et al. (2003). The role of P-glycoprotein in intestinal tumorigenesis: disruption of mdrla suppresses polyp formation in Apc(Min/+) mice. Carcinogenesis 24: 1219-1224.

Pechandova K, Buzkova H, Slanar O and Perlik F (2006). Polymorphisms of the MDR1 gene in the Czech population. Folia Biol. 52: 184-189.

Ramasamy K, Sisy Sam S and Chandrasekaran A (2006). Allele and genotype frequency of MDR1 C3435T in Tamilian population. Drug Metab. Pharmacokinet. 21: 506-508.

Sakaeda T (2005). MDR1 genotype-related pharmacokinetics: fact or fiction? Drug Metab. Pharmacokinet. 20: 391-414.

Sauna ZE, Kimchi-Sarfaty C, Ambudkar SV and Gottesman MM (2007). Silent polymorphisms speak: how they affect pharmacogenomics and the treatment of cancer. Cancer Res. 67: 9609-9612.

Schinkel AH (1997). The physiological function of drug-transporting P-glycoproteins. Semin. Cancer Biol. 8: 161-170.

Schwab M, Eichelbaum M and Fromm MF (2003). Genetic polymorphisms of the human MDR1 drug transporter. Annu. Rev. Pharmacol. Toxicol. 43: 285-307.

Tang K, Ngoi SM, Gwee PC, Chua JM, et al. (2002). Distinct haplotype profiles and strong linkage disequilibrium at the MDR1 multidrug transporter gene locus in three ethnic Asian populations. Pharmacogenetics 12: 437-450.

Turgut S, Turgut G and Atalay EO (2006). Genotype and allele frequency of human multidrug resistance (MDR1) gene C3435T polymorphism in Denizli province of Turkey. Mol. Biol. Rep. 33: 295-300.

Wasilewska A, Zalewski G, Chyczewski L and Zoch-Zwierz W (2007). MDR-1 gene polymorphisms and clinical course of steroid-responsive nephrotic syndrome in children. Pediatr. Nephrol. 22: 44-51.

Xhemo E, Fajac A, Boire JY and Levy P (2007). MDRView: a visualization of the polymorphisms of MDR1(ABCB1) gene in breast cancer. Conf. Proc. IEEE Eng. Med. Biol. Soc. 2007: 4592-4594.

Xing Q, Gao R, Li H, Feng G, et al. (2006). Polymorphisms of the ABCB1 gene are associated with the therapeutic response to risperidone in Chinese schizophrenia patients. Pharmacogenomics 7: 987-993.

Genetics and Molecular Research 7 (4): 1193-1199 (2008)

CFUNPEC-RP www.funpecrp.com.br 